\title{
Evaluation of polymorphisms in the presenilin-1 gene and the butyrylcholinesterase gene as risk factors in sporadic Alzheimer's disease
}

\author{
Louise Tilley ${ }^{1}$, Kevin Morgan ${ }^{1}$, Joe Grainger ${ }^{1}$, Peter Marsters ${ }^{1}$, Linda Morgan ${ }^{1}$, \\ James Lowe $^{2}$, John Xuereb ${ }^{3}$, Charles Wischik ${ }^{3}$, Charles Harrington ${ }^{4}$ and \\ Noor Kalsheker ${ }^{1}$ \\ ${ }^{1}$ Division of Clinical Chemistry and ${ }^{2}$ Division of Pathology, School of Clinical Laboratory Sciences, University \\ Hospital, Queen's Medical Centre, Nottingham \\ ${ }^{3}$ Department of Histopathology and ${ }^{4}$ Department of Psychiatry, University of Cambridge Clinical School, \\ Addenbrooke's Hospital, Cambridge, UK
}

The $\varepsilon 4$ allele of the apolipoprotein $\mathrm{E}$ gene $(\mathrm{APOE})$ is a major risk factor for late-onset Alzheimer's disease (LOAD) but is neither necessary nor sufficient to cause the disease. In this study, we investigated polymorphisms in the presenilin-1 (PS-1), and butyrylcholinesterase $(B C h E)$ genes, which have been implicated as risk factors for LOAD. Our data-set comprised 177 AD and 118 control patients, all of whom had been histopathologically confirmed following autopsy. We have tested homozygosity for the PS-1 allele 1 and possession of the BChE-K variant in association with APOE $\& 4$ as risk factors in LOAD. Our findings support an association between the PS-1 polymorphism and LOAD, finding homozygosity for allele 1 associated with an approximately two-fold increased risk. Our data also show that in subjects greater than 75 years of age possession of both BChE-K and APOE- 44 alleles is associated with an increased risk of LOAD, whilst the risk associated with APOE- $\varepsilon 4$ allele alone is not significant.

Keywords: Alzheimer's disease; polymorphisms; PS-1 gene; $B C h E$ gene

\section{Introduction}

Alzheimer's disease (AD) is the most common cause of dementia in the elderly. Genetic studies have shown that the apolipoprotein $\mathrm{E}$ (APOE) $\varepsilon 4$ allele is a major risk factor for both familial and sporadic $\mathrm{AD},{ }^{1}$ but it is

Correspondence: Dr K Morgan, Div. of Clinical Chemistry, School of Clinical Laboratory Sciences, University Hospital, Queen's Medical Centre, Nottingham, NG72UH, UK. Tel: +44-115-9249924 × 44751; Fax: + 44-115-9709167; E-mail: Kevin.Morgan@nottingham.ac.uk

Received 29 June 1998; revised 18 March 1999; accepted 19 March 1999 neither necessary nor sufficient for the expression of AD. ${ }^{2}$ Other genetic factors have also been implicated, acting either in conjunction with APOE $\varepsilon 4$, or alone, to increase risk of late-onset AD (LOAD).

Mutations in the presenilin-1 (PS-1) gene are known to be responsible for the majority of early-onset familial AD cases, but several studies also suggest that PS-1 may play a role in LOAD. Homozygosity for allele 1 of an intronic polymorphism in the $P S-1$ gene has been reported to be associated with a doubling of the risk for LOAD. ${ }^{3}$ This association has been confirmed by subsequent studies, ${ }^{4-8}$ but others have failed to find a significant association. ${ }^{9-12}$ 
A recent report has also implicated the butyrylcholinesterase (BChE) gene in LOAD. ${ }^{13}$ A common variant of this gene, known as the K-variant, has been demonstrated to modify the risk of LOAD in APOE $\varepsilon 4$ carriers. The risk associated with possession of both APOE $\varepsilon 4$ and BChE-K was found to be 36-fold higher than individuals with neither allele. However, two subsequent studies have failed to confirm an association between the BChE-K variant and LOAD. ${ }^{14,15}$

In this study we aimed to test two reported risk factors for LOAD, namely, homozygosity for the PS-1 allele 1, and possession of both BChE-K and APOE \&4 alleles.

\section{Materials and Methods}

\section{Patient Material}

All subjects were Caucasian. Material was obtained from the Nottingham and Cambridge brain banks. AD patients, ( $n=177 ; 67$ male, 110 female, age $81.6 \pm 8.6$ years, range 55-101) and controls, $(n=118 ; 81$ male, 37 female, age $72.8 \pm 8.7$ years, range 58-94) were histopathologically confirmed following autopsy. Diagnosis of AD was based on the CERAD protocol. ${ }^{16}$ DNA was prepared from brain tissue as previously described. ${ }^{17}$

\section{Butyrylcholinesterase (BChE) Genotyping}

The BChE-K variant was detected using the method previously described by Jensen et al. ${ }^{18}$ Primers 5' ATATTTTACAGGAAATATTGATGTA 3 ' and 5' ATTAGAGACCCACACAACTT $3^{\prime}$ are used to introduce a Mae III restriction site when amplifying the $\mathrm{K}$ allele. PCR was conducted in a final volume of $20 \mu \mathrm{l}$, containing $200 \mathrm{ng}$ of genomic DNA, $0.44 \mu \mathrm{M}$ of each primer, $10 \mathrm{~mm}$ Tris- $\mathrm{HCl}, \mathrm{pH} 8.8,50 \mathrm{~mm} \mathrm{KCl}$, $0.08 \%$ Nonidet P40, $1.5 \mathrm{~mm} \mathrm{MgCl}_{2}, 200 \mu \mathrm{M}$ dNTPs, $0.5 \mathrm{U}$ of Taq polymerase. Reactions were overlaid with mineral oil and subjected to 33 cycles of $1 \mathrm{~min}$ at $94^{\circ} \mathrm{C}, 1.5 \mathrm{~min}$ at $53^{\circ} \mathrm{C}$, and $1.5 \mathrm{~min}$ at $72^{\circ} \mathrm{C}$, followed by $10 \mathrm{~min}$ at $72^{\circ} \mathrm{C}$, and cooling to $4^{\circ} \mathrm{C}$. Subsequently, PCR products $(5 \mu \mathrm{l})$ were digested with one unit of Mae III restriction enzyme at $55^{\circ} \mathrm{C}$ for three hours, then electrophoresed through $10 \%$ polyacrylamide gel at $20 \mathrm{~mA}$ for one hour and stained with ethidium bromide. The wild-type allele (U) gives a PCR product of $137 \mathrm{bp}$, whereas the $\mathrm{K}$ variant, because of the introduction of the Mae III site, gives $115 \mathrm{bp}$ and $22 \mathrm{bp}$ bands.

\section{Presenilin-1 (PS-1) Genotyping}

The PS-1 intronic polymorphism was analysed using the method previously described by Wragg et al, ${ }^{3}$ using primers $5^{\prime}$ CACCCATTTACAAGTTTAGC 3' and 5' CACTGATTACTAATTCAGGATC 3' which introduce a Bam $\mathrm{H} 1$ restriction site into allele 2. PCR was conducted in a final volume of $25 \mu \mathrm{l}$, containing $200 \mathrm{ng}$ of genomic DNA, $200 \mu \mathrm{M}$ dNTPs, $0.35 \mu \mathrm{M}$ of each primer, $10 \mathrm{~mm}$ Tris- $\mathrm{HCl}, \mathrm{pH} 8.8,50 \mathrm{~mm} \mathrm{KCl}$, $0.08 \%$ Nonidet $\mathrm{P} 40,1.5 \mathrm{~mm} \mathrm{MgCl}_{2} \quad 0.5 \mathrm{U}$ Taq polymerase (Helena BioSciences). Reactions were overlaid with mineral oil and subjected to 35 cycles of $30 \mathrm{~s}$ at $94^{\circ} \mathrm{C}, 30 \mathrm{~s}$ at $45^{\circ} \mathrm{C}, 30 \mathrm{~s}$ at $72^{\circ} \mathrm{C}$, followed by $3 \mathrm{~min}$ at $72^{\circ} \mathrm{C}$, and cooling to $4^{\circ} \mathrm{C}$. The resulting $199 \mathrm{bp}$ PCR product $(7 \mu \mathrm{l})$ was digested with five units Bam $\mathrm{H} 1$ restriction enzyme at $37^{\circ} \mathrm{C}$ for three hours, then resolved through $3 \%$ agarose gel and stained with ethidium bromide. Allele 2 products yield $182 \mathrm{bp}$ fragment after digest, distinguishable from allele 1 uncut PCR product (199 bp).

\section{Statistical Methods}

Allele frequencies were estimated by allele counting and compared in AD and control groups by $\chi^{2}$ testing with Yates' continuity correction, or Fisher's exact test for small sample numbers, using Statistical Package for the Social Sciences (SPSS) software. Logistic regression analysis was performed using SPSS. The level of statistical significance was defined as $P<0.05$.

\section{Results}

Allele and genotype frequencies for apolipoprotein E, the BChE-K variant, and the PS-1 intronic polymorphism are shown in Tables 1-3. Genotype frequencies in each group for all loci tested were not found to deviate significantly from Hardy-Weinberg equilibrium.

The APOE $\varepsilon 4$ allele frequency was significantly higher in AD patients than in controls $\left(\chi^{2}=32.97,1 \mathrm{df}\right.$, $p<0.001)$ as previously reported in this data set. ${ }^{17}$ There are no significant differences in allele or genotype frequencies of the $\mathrm{BChE}-\mathrm{K}$ variant between $\mathrm{AD}$

Table 1 Allele and genotype frequencies of apolipoprotein $\mathrm{E}$ in Alzheimer's disease patients and controls

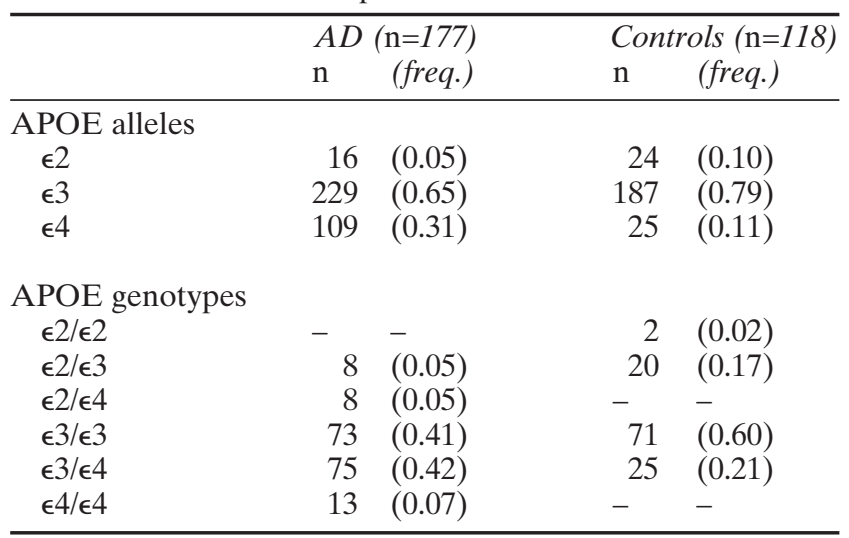

Table 2 Allele and genotype frequencies of $\mathrm{BChE}$ polymorphism in Alzheimer's disease patients and controls

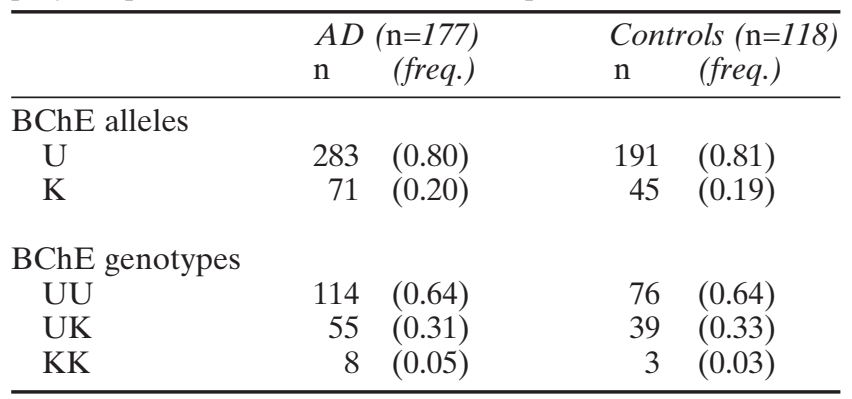


Table 3 Allele and genotype frequencies of PS-1 intronic polymorphism in Alzheimer's disease patients and controls

\begin{tabular}{lcccc}
\hline & \multicolumn{2}{c}{$A D(\mathrm{n}=177)$} & \multicolumn{2}{c}{ Controls $(\mathrm{n}=110)^{\mathrm{a}}$} \\
& $\mathrm{n}$ & (freq.) & $\mathrm{n}$ & (freq.) \\
\hline PS-1 alleles & & & & \\
$\quad 1$ & 202 & $(0.57)$ & 110 & $(0.50)$ \\
2 & 152 & $(0.43)$ & 110 & $(0.50)$ \\
& & & & \\
PS-1 genotypes & & & & \\
1:1 & 62 & $(0.35)$ & 24 & $(0.22)$ \\
$1: 2$ & 78 & $(0.44)$ & 62 & $(0.56)$ \\
$2: 2$ & 37 & $(0.21)$ & 24 & $(0.22)$ \\
\hline
\end{tabular}

${ }^{\mathrm{a}}$ Data unavailable for eight control subjects.

and control groups (Table 2) in contrast to previous findings. ${ }^{13}$ Allele and genotype frequencies for the PS-1 intronic polymorphism are shown in Table 3. Allele frequencies do not differ significantly between $\mathrm{AD}$ and control groups. However, there is an increased frequency of allele 1 homozygotes in $\mathrm{AD}$ patients as compared with controls $\left(\chi^{2}=5.64,1 \mathrm{df}, P=0.02\right)$ in agreement with previous findings. ${ }^{3}$

Logistic regression analysis was used to test previously reported findings of an associated between risk for LOAD and PS-1 allele 1 homozygosity ${ }^{3}$ and possession of both BChE-K and APOE $\varepsilon 4$ alleles. ${ }^{13}$ In order to correct for significant differences in mean age and sex distribution between the AD and control groups, these were entered as co-variants in the logistic regression analysis, along with APOE- $\varepsilon 4$ carrier status, PS-1 allele 1 homozygosity, BChE-K carrier status and combined BChE-K/APOE- $\varepsilon 4$ carrier status. Since possession of both BChE-K and APOE $\varepsilon 4$ alleles has been reported to confer most risk in the over 75 age group, the logistic regression analysis was carried out in all subjects (age $\geq 55$ years) and in only those over 75 years of age ( $140 \mathrm{AD}, 52$ controls). Estimated odds ratios from the logistic regression analyses are shown in Tables 4 and 5 .

Table 4 Logistic regression for the effects of APOE $\in 4$, PS-1 allele 1 and BChE-K alleles on risk for LOAD in subjects 55 years of age

\begin{tabular}{|c|c|c|c|}
\hline Variable & $\begin{array}{l}\text { Estimated } \\
\text { OR }\end{array}$ & $95 \% C I$ & $\mathrm{P}$-value \\
\hline APOE $\epsilon 4$ carrier & 2.77 & $1.32-5.81$ & $<0.01$ \\
\hline PS- 1 allele 1 homozygosity & 2.01 & $1.06-3.98$ & 0.03 \\
\hline BChE-K carrier & 0.67 & $0.31-1.42$ & 0.29 \\
\hline $\mathrm{BChE}-\mathrm{K} / \epsilon 4$ carriers & 3.54 & $0.94-13.34$ & 0.06 \\
\hline
\end{tabular}

Variables entered into the logistic regression model were: age, sex, APOE- $\epsilon 4$ carrier status, PS-1 allele 1 homozygosity, BChE-K carrier status, and combined BChE-K/APOE- $\epsilon 4$ carrier status.
Table 5 Logistic regression for the effects of APOE $\epsilon 4$, PS-1 allele 1 and BChE-K alleles on risk for LOAD in subjects 75 years of age

\begin{tabular}{lclc}
\hline Variable & Estimated & & \\
OPOE $\epsilon 4$ carrier & 2.36 & $0.93-6.03$ & 0.07 \\
PS-1 allele 1 homozygosity & 2.87 & $1.15-7.16$ & 0.02 \\
BChE-K carrier & 0.64 & $0.24-1.70$ & 0.37 \\
BChE-K/ $\epsilon$ 4 carriers & 13.84 & $1.28-149.27$ & 0.03 \\
\hline
\end{tabular}

Variables entered into the logistic regression model were: age, sex, APOE- $\epsilon 4$ carrier status, PS- 1 allele 1 homozygosity, BChE-K carrier status, and combined BChE-K/APOE- $\epsilon 4$ carrier status.

As expected, possession of the APOE $\varepsilon 4$ allele is associated with a significantly increased risk of LOAD $(\mathrm{OR}=2.77,95 \% \mathrm{CI}, 1.32-5.81, P<0.01)$ in subjects $\geq 55$ years of age. However, in the $\geq 75$ years age group, the APOE $\varepsilon 4$ effect becomes non-significant. The reduction of the APOE- $\varepsilon 4$ effect with increasing age has been previously reported. ${ }^{19}$ Homozygosity for the PS- 1 allele 1 is associated with an approximately two-fold increased risk (OR $=2.01,95 \% \mathrm{CI}, 1.06-3.98$, $P=0.03$ ), and this effect remains significant in the over 75 age group. The frequency of PS-1 allele homozygosity does not differ significantly between APOE $\varepsilon 4$ carriers and non-carriers in either $\mathrm{AD}$ patients or controls (data not shown), suggesting that the PS-1 effect is independent of APOE $\varepsilon 4$ status.

The logistic regression analyses show that possession of the BChE-K allele alone has no significant effect in either age group. However, possession of both BChE-K and APOE $\varepsilon 4$ alleles is associated with a significantly increased risk of LOAD in the $\geq 75$ year age group only $(\mathrm{OR}=13.8,95 \% \mathrm{CI}, 1.28-149.27, P=0.03)$.

\section{Discussion}

Although the APOE $\varepsilon 4$ is a well established risk factor for LOAD, it is estimated to account for, at most, only $50 \%$ of the total genetic effect in $\mathrm{AD}^{20}$ Thus, many studies have been directed towards the identification of further genes which may play a role in LOAD. Various putative $\mathrm{AD}$ risk factors have been investigated, but studies have failed to yield consistent results. This may be due to population differences, or heterogeneity in terms of classification of $\mathrm{AD}$, which may cause a problem when diagnosis is made on clinical grounds only. In this study, autopsy-confirmed material was used exclusively for both $\mathrm{AD}$ and control groups, resulting in a stringent definition of the phenotype. Two putative LOAD risk factors were investigated in this study: 
homozygosity for the PS-1 allele 1 , and possession of both BChE-K and APOE $\varepsilon 4$ alleles.

The BChE-K variant has recently been implicated in LOAD, with Lehmann et al reporting an odds ratio of 36 associated with possession of both the APOE $\varepsilon 4$ and BChE-K allele in the $\geq 75$ age group, whilst the effect of the APOE $\varepsilon 4$ allele alone is not significant. ${ }^{13}$ In this study we do not find a significantly increased frequency of the BChE-K allele in AD patients as compared with controls, in contrast to the finding of Lehmann et al. ${ }^{13}$ However, our findings do support an increased risk of LOAD associated with possession of both APOE $\varepsilon 4$ and BChE-K in the over 75 age group, with an odds ratio of 13.8. In our $\mathrm{AD}$ patient group, possession of the BChE-K allele produces an apparent reduction in the risk of $\mathrm{AD}$ (non-significantly), whereas possession of both APOE $\varepsilon 4$ and BChE-K alleles results in an increased risk (Tables 4 and 5) which becomes significant in the older age group. Clearly this effect merits further study. To confirm the role of the BChE-K allele in LOAD, further studies using considerably larger data sets are required, since in both this study and that of Lehmann et $a l,{ }^{13}$ there are very small numbers in the control group possessing both APOE \&4 and BChE-K alleles, resulting in very large confidence intervals; this may be contributing to the apparent dichotomy of the BChE-K allele effect.

Our data also show that homozygosity for allele 1 of the $P S-1$ gene is associated with an approximate doubling of LOAD risk, as reported by Wragg et al. ${ }^{3}$ In this study the effect of PS- 1 allele 1 homozygosity is significant both in the $\geq 55$ year and $\geq 75$ year age groups, and is apparently independent of APOE $\varepsilon 4$ status. These results are in agreement with Wragg et $a l^{3}$ who also found that PS-1 allele 1 homozygosity was a significant risk factor in AD patients aged 65 years or less, and for cases over the age of 65 years. However, it should be noted that in our study this is of borderline significance $(0.01<P<0.05)$ and excess of PS- 1 allele homozygotes in our AD group is largely at the expense of heterozygotes; the frequency of PS- 1 allele 2 homozygotes is similar in our $\mathrm{AD}$ and control groups (Table 3). This is further highlighted by the fact that the odds ratio associated with PS-1 allele 1 homozygosity, taking allele 2 homozygotes as reference (rather than combined heterozygotes and allele 2 homozygotes), is not significant $(\mathrm{OR}=1.68,95 \% \mathrm{CI}, 0.83-3.36)$. The PS-1 intronic polymorphism may be functionally significant or may be linked to a functional mutation elsewhere in the $P S-1$ gene. Wragg et $a l^{3}$ failed to find any coding sequence changes linked to allele 1 of the PS-1 gene. However, there may still be genetic variability in the non-coding regions of the gene which remains to be found.

In conclusion, in this study we support an association between the PS-1 intronic polymorphism and LOAD, with an approximate doubling of risk associated with homozygosity for allele 1 . The $\mathrm{BChE}-\mathrm{K}$ variant will require further studies on much larger groups than used hitherto, to confirm its action as a risk modifier in association with the APOE $\varepsilon 4$ allele.

\section{Acknowledgements}

We thank the Trent Health Research Scheme for support of this study and Nottingham University for the studentship for LT.

\section{References}

1 Strittmatter WJ, Saunders AM, Schmechel D et al: Apolipoprotein-E-high-avidity binding to beta-amyloid and increased frequency of type-4 allele in late-onset familial Alzheimer's disease. Proc Natl Acad Sci USA 1993; 90: 1977-1981.

2 Polvikoski T, Sulkava R, Haltia M et al: Apolipoprotein-E, dementia, and cortical deposition of beta-amyloid protein N Engl J Med 1995; 339: 1242-1247.

3 Wragg M, Hutton M, Talbot C et al: Genetic association between intronic polymorphism in presenilin-1 gene and late-onset Alzheimer's disease. Lancet 1996; 347: 509-512.

4 Kehoe P, Williams J, Lovestone S, Wilcock G, Owen MJ: Presenilin-1 polymorphism and Alzheimer's disease (letter). Lancet 1996; 347: 1186.

5 Higuchi S, Muramatsu T, Matsushita S, Arai H, Sasaki H: Presenilin-1 polymorphism and Alzheimer's disease (letter). Lancet 1996; 347: 1186.

6 Ezquerra M, Blesa R, Tolosa E et al: The genotype 2/2 of the presenilin-1 polymorphism is decreased in Spanish early-onset Alzheimer's disease. Neurosci Lett 1997; 227: 201-204.

7 Isoe K, Urakami K, Ji Y, Adachi Y, Nakashima K: Presenilin-1 polymorphism in patients with Alzheimer's disease, vascular dementia and alcohol-associated dementia in Japanese population. Acta Neurol Scand 1996; 94 326-328.

8 Matsushita S, Arai H, Muramatsu $\mathrm{T}$ et al: Presenilin-1 polymorphism in Alzheimer's disease and vascular dementia. Exp Neurol 1997; 146: 567-569.

9 Scott WK, Roses AD, Haines JL, Pericak-Vance MA: Presenilin-1 polymorphism and Alzheimer's disease (letter). Lancet 1996; 347: 1560.

10 Perez-Tur J, Warrantdevrieze F, Lambert JC, ChartierHarlin MC: Presenilin-1 polymorphism and Alzheimer's disease (letter). Lancet 1996; 347: 1560. 
11 Tysoe C, Whittaker J, Cairns NJ et al: Presenilin-1 intron 8 polymorphism is not associated with autopsy-confirmed late-onset alzheimer's disease. Neurosci Lett 1997; 222: 68-69.

12 Tysoe C, Galinsky D, Robinson D et al: Analysis of alpha1-antichymotrypsin, presenilin-1, angiotensin-converting enzyme, and methylenetetrahydrofolate reductase loci as candidates for dementia. Am J Med Gen 1997; 74: 207-212.

13 Lehmann DJ, Johnston C, Smith AD: Synergy between the genes for butyrylcholinesterase $\mathrm{K}$ variant and apoliprotein E4 in late-onset confirmed Alzheimer's disease. Hum Mol Genet 1997; 6: 1933-1936.

14 Brindle N, Song E, Rogaeva SE et al: Analysis of the butyrylcholinesterase gene and nearby Chromosome 3 markers in Alzheimer's disease. Hum Mol Genet 1998; 7: 933-935.

15 Singleton AB, Smith G, Gibson AM et al: No association between the $\mathrm{K}$ variant of the butyrylcholinesterase gene and pathologically confirmed Alzheimer's disease. Hum Mol Genet 1998; 7: 937-939.
16 Mirra SS, Heyman A, McKeel D et al: The consortium to establish a registry for Alzheimer's disease (CERAD). Part II. Standardisation of the neuropathologic assessment of Alzheimer's disease. Neurology 1991; 41: 479-486.

17 Morgan K, Morgan L, Carpenter K et al: Microsatellite polymorphism of the alpha-1-antichymotrypsin gene locus associated with sporadic Alzheimer's disease. Hum Genet 1997; 99: 27-31.

18 Jensen FS, Nielsen LR, Schwartz M: Detection of the plasma cholinesterase-K variant by PCR using an amplification-created restriction site. Hum Hered 1996; 46: 26-31.

19 Bickeboller H, Campion D, Brice A et al: Apolipoprotein $\mathrm{E}$ and Alzheimer's disease: genotype-specific risks by age and sex. Am J Hum Genet 1997; 60: 439-446.

20 Roses AD, Devlin B, Coneally PM et al: Measuring the genetic contribution of APOE in late-onset Alzheimer's disease (AD) (abstract). Am J Hum Genet 1995; 57 (suppl): A202. 